\title{
The Role of Cognitive Dysfunction and Behavioral Activation System on Life Quality Life of Employees in Iran
} \author{
University, Bandar Abbas, Iran \\ University, Bandar Abbas, Iran \\ Study Area: Bandar Abbas, Iran \\ Coordinate: $27^{\circ} 11^{\prime} \mathrm{N} ; 56^{\circ} 16^{\prime} \mathrm{E}$
}

Abbas Darkhor', Maryam Sadeghifard ${ }^{2 *}$

${ }^{1}$ Department of Psychology, Bandar Abbas Branch, Islamic Azad

${ }^{2}$ Department of Counseling, Bandar Abbas Branch, Islamic Azad

Key words: Anxiety, Stress, Fatigue, Sleepiness, Affective disorders

\section{Abstract}

The role of cognitive dysfunction and Behavioral Activation System on the quality of life of employees has been tried to understand. In this study, we considered all the employees of Azad University of Bandar Abbas working in the year 2016 as subject. Using simple random sampling method, 90 employees of Azad University, Bandar Abbas were selected and data were collected by using Cognitive dysfunction, behavioral activation system and quality of life questionnaires. Obtained data were analyzed by using Pearson correlation coefficient and using SPSS software and the result revealed a significant and negative relationship between the quality of life with cognitive dysfunctions, including distraction, memory problems, unintentional mistakes and inability to memorize the names. Nevertheless, a significant and positive relationship between these cases and Behavioral Activation System has also been evidenced. Our results concluded that cognitive dysfunction and Behavioral Activation System are factors that affecting the quality of life.

\section{Introduction:}

Accordingly, quality of life for different people in different situations has different definitions, but in principle, it refers to personal satisfaction from life (Ayat-Elahi \& Raf iei, 2004). A number of researchers consider the quality of life something individual and dependent on the specif ic understanding of person from psychological, social, economical, cultural, religious and sexual aspects of life (Hemmati, 2006).

One of the psychological and effective aspects of people's quality of life is cognitive dysfunction. Cognitive dysfunctions are mistakes or errors that a person makes when carries out tasks and he or she is normally able to do them, in other words, cognitive dysfunction is a multidimensional construct that includes errors in shaping purposes, schema activation and errors in the start-up of actions (Wallace et al., 2002). Cognitive dysfunction due to interference in routine activities could lead to fundamental problems; sometimes compensation of such errors takes a long time. As per Broadbent (1982), cognitive dysfunction includes distraction, memory problems, unintentional mistakes and inability to remember names. Gray \& McNaughton (2000) in a review of human research in the reinforcement of sensitivity theory (RST) proposed the character as a biological model which includes three mental-behavioral systems. They believe that such mental-behavioral systems are the basis leads to different emotional reactions, such as early provocation, anxiety and fear.

The first system is Behavioral Activation System (BAS) which response to the conditional stimulus of reward and lack of punishment and the sensitivity of BAS system represent impulsivity of the person (Gray, 1995). The second system is behavioural inhibition system (BIS) which response to a conditional stimulus of lack of reward and punishment and new stimuli and inherent frightening stimulus (Gray \& McNaughton, 2000). Activation of this system calls the emotional state of anxiety, behavioural inhibition, passive avoidance, silence, increasing attention and establishment. Regarding the role of stressful events on health and disease in recent researches, index of mild events such as distress as moderators takes into consideration the relationship between experiencing distress and incidence of disease. Some studies, including researches by Kanyazev \& Slobodskoj-Plusnin (2007), Heponiemi et al. (2003) stated that emotional sensitivity is stronger than bothering of individual differences and activation of each of them

*Corresponding Author: m.n.psychology1986@gmail.com 
distresses in people with strong inhibition system. Kingsburya et al. (2013) stated that Behavioral Activation System has a significant relationship with high indices of social and emotional performances. Erdle \& Rushton (2010) stated that Behavioral Activation System has a positive and significant relationship with the expectation of reward, high self-esteem and positive effect while it has a significant and negative relationship with expectations of punishment and affection. Research results revealed the proper significant relationship between inhibition systems with pathological and non-pathological anxiety. Inhibition System had a positive and meaningful impact on the concerns. There was no significant relationship between activation system with concerns and activation system didn't have a positive and significant impact on concerns (Mansouri \& Roodsari, 2010). Thus, this study seeks to answer the question that- whether any impact by cognitive dysfunction and Behavioral Activation System in the quality of life of employees exists?

\section{Methodology:}

The method of this study is correlational. for investigating the role of cognitive failure and Behavioral Activation System in the quality of life in employees. We included all employees of the Azad University of Bandar Abbas as the subject of this study and by random sampling method, total go employees were selected as the sample group.

Data Collection Instruments: After coordination with Azad University, explaining the purpose of research to be employed on the staffs of University and getting proper consent, research tools i.e., questionares on Cognitive Failures Questionnaire, Gray-Wilson Personality Questionnaire (GWPQ), and Quality of Life Scale (mental and physical condition) were forwarded to answer.

Data-analysis: analysis was first performed in a descriptive form which included mean, standard deviation, etc. To test the hypotheses in the second part, correlational in the SPSS software was employed.

\section{Results:}

\section{Results are summerized in Table to to 4:}

Table-1: Frequency distribution \& sexuality percentage of respondents

\begin{tabular}{lll}
\hline Sexual distribution & Frequency & Percentage \\
\hline Female & 37 & 41.11 \\
Male & 53 & 58.88 \\
Total & 90 & 100 \\
\hline
\end{tabular}

Table 2: Frequency distribution \& percentage of respondents' age

\begin{tabular}{lll}
\hline Age distribution & Frequency & Percentage \\
\hline Lowerthan 30 & 21 & 23.33 \\
$31-40$ & 27 & 30 \\
$41-50$ & 25 & 27.77 \\
Upper than 50 & 17 & 18.88 \\
Total & 90 & 100 \\
\hline
\end{tabular}

Ambient Science (2016)
The first illatuion of this study was:

1. There is a relationship between cognitive dysfunction and quality of life of employees.

2. There is a relationship between distraction and quality of life of employees.

3. There is a relationship between the problems related to memory and quality of life of employees.

4. There is a relationship between unintentional mistakes and quality of life of employees.

5. There is a relationship between inability to remember names and quality of life of employees.

To test this hypothesis the Pearson correlation coeff icient test was used and results of which are reported in the following tables.

Table 3.4: Correlation coeff icient of cognitive dysfunction with quality of life

\begin{tabular}{llr}
\hline Variable & Statistic & $\begin{array}{r}\text { Quality } \\
\text { oflife }\end{array}$ \\
\hline Distraction & Correlation coefficient & -0.30 \\
Problems of memory & Significancelevel & 0.003 \\
& Correlation coefficient & -0.46 \\
Unintentional mistakes & Significancelevel & 0.000 \\
& Correlation coefficient & -0.23 \\
Inability to remember & Significancelevel & 0.02 \\
names & Correlation coefficient & -0.48 \\
Cognitivedysfunction & Significancelevel & \\
& Correlation coefficient & -0.000 \\
& Significancelevel & 0.004 \\
\hline
\end{tabular}

According to Table-3, there is a significant negative relationship $(\mathrm{p}<0.05)$ between quality of life with distraction $(\mathrm{r}=-0.30)$, problems of memory $(\mathrm{r}=-0.46)$, unintentional mistakes ( $\mathrm{r}=-0.23)$, inability to remember names $(\mathrm{r}=-0.48)$, and cognitive dysfunction $(\mathrm{r}=-0.29)$. Based on these results the first hypothesis of the study is affirmed and it could be said that, with increase in each unit of cognitive dysfunction quality of life would be decreased.

The second illatuion of this study was:

1. There is a relationship between Behavioral Activation System and quality of life of employees.

To test this hypothesis the Pearson correlation coeff icient test was used and results of which are reported in the following tables.

Table-4: Correlation coefficient of cognitive dysfunction with quality of life

\begin{tabular}{llr}
\hline Variable & Statistic & $\begin{array}{r}\text { Quality } \\
\text { oflife }\end{array}$ \\
\hline Behavioralactivation & Correlation coefficient & $\mathbf{0 . 2 2}$ \\
& Significancelevel & 0.03 \\
\hline
\end{tabular}

According to Table-4, there is a positive significant relationship $(\mathrm{p}<0.05)$ between quality of life and Behavioral Activation System $(\mathrm{r}=-0.30)$. Based on these 
results the second hypothesis of study is affirmed and it can be said that, with increase in each unit of Behavioral Activation System, quality of life will be decreased.

\section{Discussion:}

This study was conducted to investigate the role of cognitive dysfunction and Behavioral Activation System in the quality of life of employees. The first aim of this study was: do any relationship between cognitive dysfunctions (distraction, problems of memory, unintentional mistakes and inability to remember names) and quality of life of the employee. Results of study have shown that there is a positive significant relationship between cognitive dysfunction and alexithymia with procrastination in the decision-making of students (Abbasi et al., 2015). The relationship is tested between cognitive dysfunction, anxiety, stress fatigue, sleepiness and affective disorders (Mecacci et al., 2004). The obtained results in this study are consistent with the results of Gholyan et al. (2010), Barati \& Arizi (2010), and Piras et al., (2015). Cognitive dysfunctions due to interference with daily activities can lead to fundamental problems. Sometimes it takes a long time to compensate these errors. When such errors occur at startup stage of actions, they may cause serious injuries and even death (Doorn et al., 2010). Cognitive dysfunction includes disorders in attention (for example failure of perception), memory (failure to remind insufficiency) and motor function (movement disorders). Reason (1988) states that, people who commit cognitive dysfunction have limited memory. In other words, cognitive dysfunction is a multi-dimensional structure which contains errors in shaping goals, mistake in activation of schemes and error in setup of actions (Wallace et al., 2002).Distraction is a psychological phenomenon that causes many problems. For example decline in quality of life due to inability to remember names, distraction, etc. can be mentioned.

The second aim of this study was: do a relationship exist between Behavioral Activation System and quality of life of employees. To investigate this hypothesis the Pearson correlation coefficient test was used. The results revealed a significant relationship between quality of life and Behavioral Activation System. The obtained results from this study resemble with the results of studies by Zoljanahi \& Vafaei (2006), Hosseini et al. (2007), Gomez \& Gomez (2009), Erdle \& Rushton (2010) and Li et al. (2015). Behavioural Activation System is activated by pleasant stimulus associated with reward or omission of punishment. Two behavioural components of this system include the choice of behaviour (active search of rewards) and active avoidance (providing specific behaviours to avoid punishment). The sensitivity of this system represents a person's impulsivity and early provocation which is responsible for experiences such as hope, joy and happiness. It is assumed that Behavioral Activation System is the fundamental trait of early provocation and is related to motivation, extroversion and sensation-seeking.This system activates when a person faces with different emotions and is happy and according to these emotions will respond to situations that can enhance the quality of life for a person. As a result, behavioural activation system causes the activation of choosing a system and passive avoidance and this makes happiness in person, which in turn enhances the quality of life (Huang et al, 2006).

The quality of life is one of the most fundamental concepts in positive psychology. Due to the importance and broad scope of quality of life in the field of positive psychology, till date effecting factors on it were investigated randomly. Among the social factors, a role of family and way of communication between members seems very basic in the formation of a quality of life. The quality of life includes different aspects of health and physical, emotional and social comfort and it changes the experience of the person and his understanding of life over time. Each dimension has both subjective and objective measurable aspects but one's expectations and mental desires represents the real experienced quality of life (Tayebi et al., 2010). Subjective quality of life refers to the fact that it should be determined based on the person's own idea, not the substituted person. Dynamism means that it will change over time and therefore it is necessary to be measured during a period of time. Health-related quality of life considers a person's mental evaluation of his current health status, health care and health-promoting activities that improve some levels of overall activities and let the person to pursue worthy goals of his life. Based on our obtained results, it could be concluded that cognitive dysfunction and Behavioral Activation System are the factors affecting the quality of life.

Acknowledgements:

We thank to all the participants who were the subjects in our study.

\section{References:}

Abbasi, M., Zabih, P., Shahriar, D., \& Shabnam, A.N. (2015): The relationship between cognitive dysfunction and alexithymia and decisional procrastination in students. Iran. J. Med. Edu., 14(10): 898-908.

Ayat-Elahi, S.M.T. \& Raf iei M. (2004) . Investigating quality of life among the personnel of Islamic Azad University of Arak in 2003. . Men. Health Princ., 6: 70-63.

Barati, H. \& Arizi, H.R. (2010).Comparison of cognitive dysfunction and meta-cognitive componentsand considering modification variable in occupational accidents.J. Behav. Sci., 4(2): 121-115.

Broadbent, D.E., Cooper, P.F., Fitzgerald, P. \& Parkes, K.R.(1982): The cognitive failures questionnaire (CFQ) and its correlates. Brit.JClin Psychol.,21(1):1-16.

Doorn, R.R.A., Lang, J.W.B., Weijters, T. (2010): Selfreported cognitive failures: A core self-evaluation? Pers.Indiv.Differ., (49):717-722. 
Erdle, S. \& Rushton, J.P.(2010): The General Factor of Personality, BISBAS, expectancies of reward and punishment, selfesteem, and positive and negative affect. Pers. Indiv. Differ. (48): $762-766$.

Gomez, A. \& Gomez, R. (2002): Personality traits of the behavioural approach and inhibition systems: associations with processing of emotional stimuli. Pers. Indiv. Differ., 32(8):1299-1316

Gray, J.A. (1995): A model of the limbic system and basal ganglia: Applications to anxiety and schizophrenia. In M. Gazzaniga (Ed.), The cognitive neuroscience. Cambridge: MIT Press, pp. 11651176.

Gray, J.A. \& McNaughton, N. (2000): The Neuropsychology of Anxiety: An Enquiry into the Functions of the SeptoHippocampal System. Oxford: Oxford University Press.

Gholyan, M.S., Falaha, P.A., Ashteyani, F. \& Ashayeri, H. (2010): The relationship between extraversion and neuroticism with cognitive dysfunction: assessment of the role of mediating meta-cognitive. J.Clin.Psych., 4(2):48-41.

Hosseini, J., Bidgoli, I. \& Ghoushchian, S. (2007): Comparison of activity of mental-behavioral system in patients with obsessive-compulsive disorder and normal people. Cogn. Sci., 9(4):16-25.

Hemmati, Kh. (2006): Investigating and comparison of attitudes towards disabled people and ordinary people towards quality of life and its dimensions, Master Thesis, University of Shiraz.

Heponiemi, T., Keltikangas-Järvinen, L., Puttonen, S. \& Ravaja, N.(2003): BIS/BAS sensitivity and self- rated affects during experimentally induced stress. Pers. Indiv. Differ., 34(6): 943957.

Huang, C., Wu, A. W., \& Frangakis, C. (2006): Do the SF-36 and WHOQOL-BREF measure the same constructs? Evidence from the Taiwan population. Qual. Life Res., 15:15-24.
Kanyazev, G.G. \& Slobodskoj-Plusnin, J.Y.U. (2007):Behavioral approach system as a moderator of emotional arousal elicited by reward and punishment cues. Pers. Indiv. Differ., 42(1): 4959.

Kingsburya, A., Coplan, R.J., Weeks, M. \& Rose-krasnor, L.(2013): Covering all the BAS's: A closer look at the links between BIS, BAS, and socio-emotional functioning in childhood. Pers. Indiv. Differ. , 55(5):521-526.

Li, Y., Xu, Y. \& Chen, Z. (2015).Effects of the behavioral inhibition system (BIS), behavioral activation system (BAS), and emotion regulation on depression: A one-year follow-up study in Chinese adolescents. Psychiatry Res.,230(2):287-293.

Mansouri, A. \& Roodsari, A.B. (2010): The relationship between activation systems and behavioral inhibition with pathological and non- pathological worry. J. Babol Univ. Med. Sci., 12(1): 64-59.

Mecacci, L., Righi, S., \& Rocchetti, G. (2004): Cognitive failures and circadian typology. Pers. Indiv. Differ.,37(1):107-113.

Piras, F., Orfei, M.D., Caltagirone, C. \& Spalletta, G. (2016): Selfawareness in Mild Cognitive Impairment: Quantitative evidence from systematic review and meta-analysis. Neurosci. E Biobehav. Rev., 61: 90-107.

Reason, J. (1988): Stress and cognitive failure, in S. Fisher \& Reason J (eds.) Handbook of life stress, cognition, and health. New York: Wiley.

Tayebi, A., Salimi, S.H., Mahmoudi, H. \& Tadrisi, S.D. (2010): Comparison of quality of life in dialysis and kidney transplantation patients. LCrit. Care Nurs. 3(1):19-22.

Wallace, J.C., Kass, S.J. \& Stanny, C.J. (2002): Cognitive failures questionnaire revisited: correlates and dimensions. J. Gen. Psychol., 129(3): 238-256.

Zoljanahi, E. \& Vafaei, M. (2006): The relationship between type D personality with behavioral inhibition and behavioral activation systems, Journal of Psychology, University of Tabriz, Volume 1, No. 2 and No. 3, pp. 15-8.

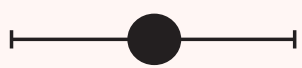

